$12-1-2020$

\title{
Investing in social and behavior change is cost-effective for increasing modern contraceptive use in Niger
}

Breakthrough RESEARCH

Follow this and additional works at: https://knowledgecommons.popcouncil.org/departments_sbsr-rh How does access to this work benefit you? Let us know!

Recommended Citation

Breakthrough RESEARCH. 2020. "Investing in social and behavior change is cost-effective for increasing modern contraceptive use in Niger," Breakthrough RESEARCH Programmatic Research Brief. Washington, DC: Population Council. 


\section{Investing in social and behavior change is cost-effective for increasing modern contraceptive use in Niger}

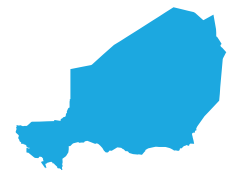

Social and behavior change (SBC) interventions are generally considered an essential part of high-quality health services, yet gaps in information on the cost and impact of SBC means decision-makers have under-appreciated the value of SBC for contributing to improved health outcomes. To address this issue, Breakthrough RESEARCH has leveraged evidence from 153 studies on family planning (FP) SBC impact and 70 studies on SBC costs to assess the cost-effectiveness of SBC programming for FP as part of its Business case for Investing in Social and Behavior Change for Family Planning.

\section{Overall findings}

A review of the literature found that SBC increases modern contraceptive use. Studies show that SBC positively influences intermediate determinants that impact modern contraceptive use, such as attitudes, partner communication and others. The strength of impact varies by the type of SBC intervention and which intermediate outcome is targeted (Figure 1).

Results indicate that FP SBC interventions are highly cost-effective. The cost per disability adjusted life year $(D A L Y)^{1}$ averted is a common metric for assessing cost-effectiveness. SBC Investment case scenarios were modeled in Guinea, Niger, Togo, and Zambia. In each country, the resulting cost per DALY averted indicates that SBC investments for FP are highly cost-effective based on the World Health Organization (WHO) benchmarks.

Doubling FP SBC investments allows programs to address equity and tackle more complex barriers to modern contraceptive use. Additional SBC investments focused on interpersonal communication (IPC), community awareness raising activities, and multi-component packages of SBC interventions in Togo and Niger increased expected modern contraceptive use and were still cost-effective.

FIGURE 1: SBC IMPACT PATHWAYS TO INCREASED MODERN CONTRACEPTIVE USE (UPDATED)

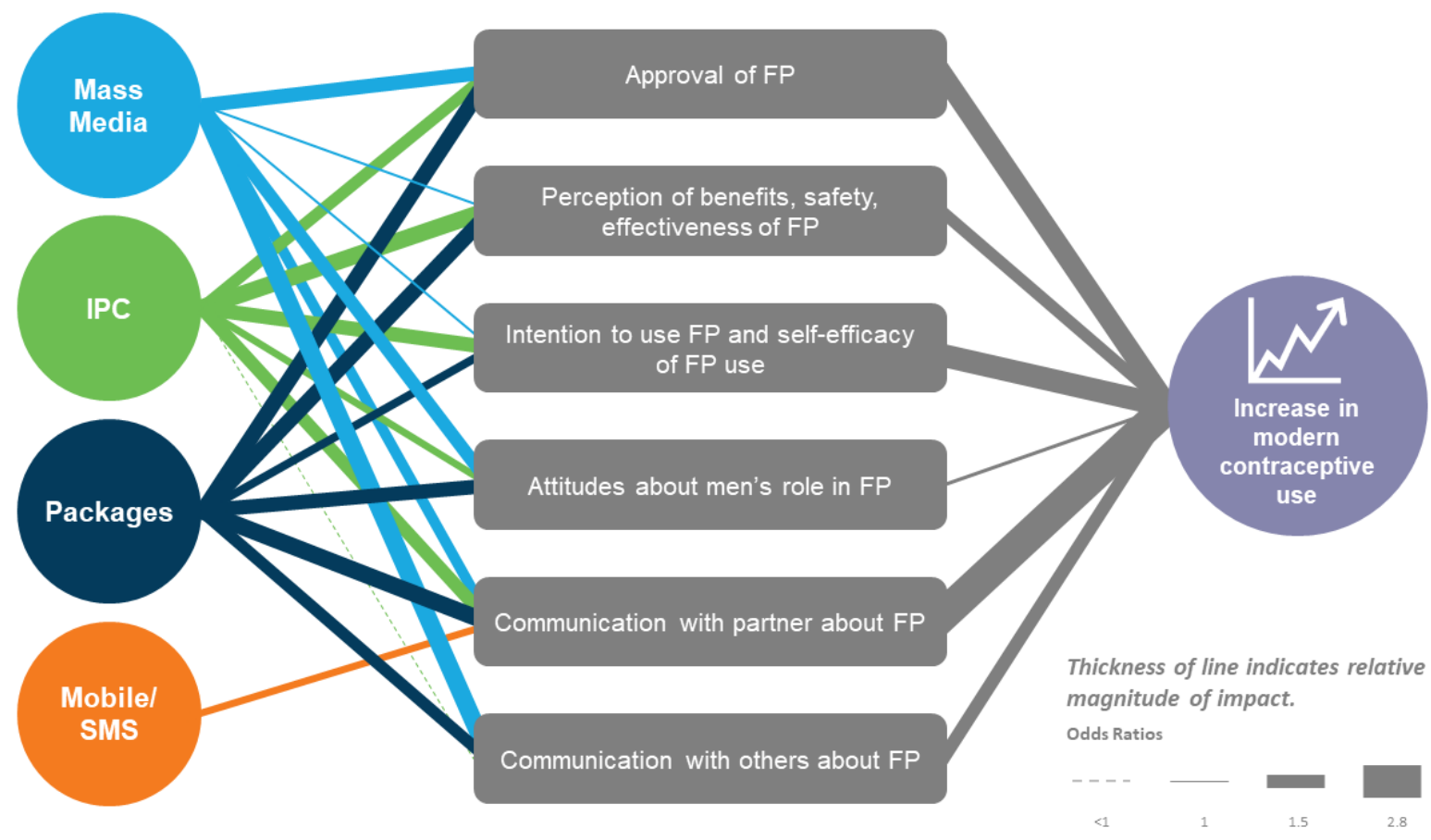

This graphic incorporates data from 153 studies, including an additional 23 studies since the original FP business case for SBC was published in October 2019. The "perception of benefits, safety, effectiveness of FP" pathway found in other applied business cases was not modeled due to lack of available data for this indicator in Niger. 


\section{SBC for FP: A cost-effective investment in Niger}

The Breakthrough RESEARCH Business Case modeled SBC cost-effectiveness in Niger utilizing two investment scenarios to assess the impact of SBC programming on modern contraceptive use.

1. The national plan scenario was based on planned investments documented in Niger's Family Planning in Niger: 2012-2020 Action Plan and the Family Planning in Niger: 2018 Operational Plan. The national plan indicated a cumulative five-year investment of approximately $\$ 5.5$ million dollars in SBC for FP.

2. A double-investment scenario examined the effects of doubling the Niger national plan total investment to \$11.1 million with the increased investments targeting community awareness raising activities and group IPC for youth, focused largely on peer education.

\section{Impact}

In Niger, the 2020 modern contraceptive prevalence rate (mCPR) was 16.0\%. Over five years (2021-2025), SBC investments based on the national plan are estimated to yield a 2.3 percentage point increase in $\mathrm{mCPR}$, approximately 128,000 averted unintended pregnancies, and 22,000 maternal DALYs saved. ${ }^{2}$ The double-investment scenario generated a 3.4 percentage point gain, averting approximately 192,000 pregnancies and saving nearly 33,000 maternal DALYs.

\section{FIGURE 2: CONTRIBUTION OF SBC INTERVENTIONS TO INCREASING MODERN CONTRACEPTIVE USE IN NIGER

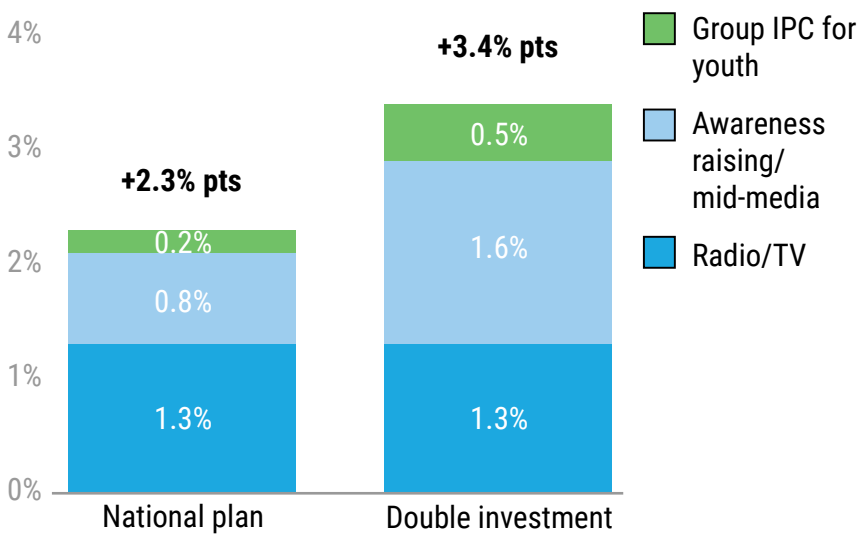

\section{Cost}

In addition to the SBC investment costs, direct service delivery costs for the additional users of modern contraception result in a total estimated cost of $\$ 8.2$ million for the national plan scenario and \$15.1 million for the double-investment scenario. ${ }^{3}$

\section{Cost-effectiveness}

The results for the first SBC intervention scale-up scenario is considered highly cost-effective based on the WHO standard of less than one times the gross domestic product (GDP) per capita in Niger of $\$ 414 .{ }^{4}$ The double-investment scenario is above one times the GDP per capita, but below three times the GDP per capita, and thus considered "cost-effective". If compared to the average GDP benchmark for low- and middle-income countries in sub-Saharan Africa (SSA) at $\$ 1,612$, the cost-effectiveness of both investment scenarios are highly cost-effective.

The double-investment scenario has a higher cost per DALY averted because the additional investments were directed toward higher cost interventions aimed to reach those without access to mass media and to address more challenging barriers to FP use by engaging in IPC.

\section{FIGURE 3: NIGER COST-EFFECTIVENESS RESULTS}
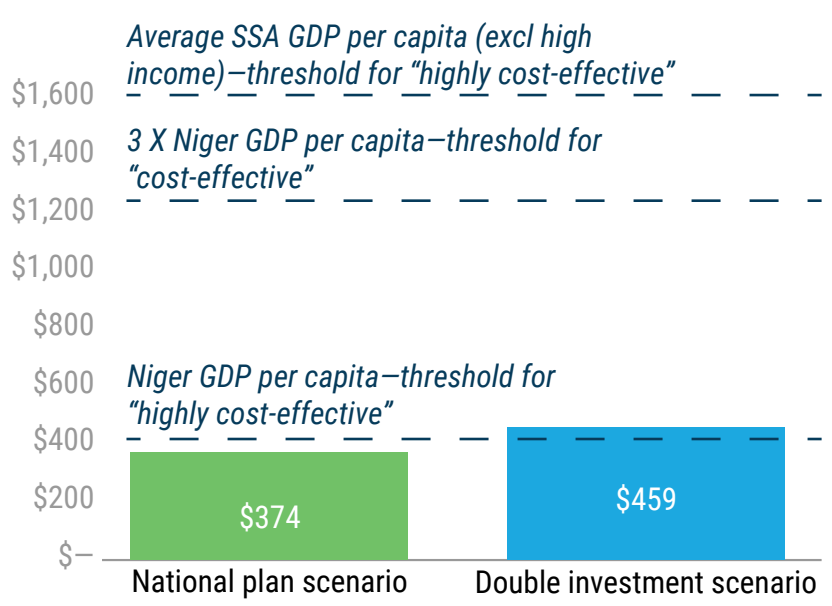

\footnotetext{
${ }^{1 " O n e ~ D A L Y ~ c a n ~ b e ~ t h o u g h t ~ o f ~ a s ~ o n e ~ l o s t ~ y e a r ~ o f ~ ' h e a l t h y ' ~ l i f e . ~ T h e ~ s u m ~ o f ~}$ DALYs across the population, or the burden of disease, can be thought of as a measure of the gap between current health status and an ideal health situation where the entire population lives to an advanced age, free of disease and disability." (WHO, https://www.who.int/healthinfo/global_burden_disease/metrics_daly/en/, date accessed 29 October 2019).

${ }^{2}$ The estimated increase in modern contraceptive prevalence is in addition to annual increases due to non-SBC interventions.

${ }^{3}$ Based on median cost estimates from global unit costs and assumed scaleup scenarios; actual costs in Niger may vary.

'The WHO's threshold for a highly cost-effective intervention is a cost per DALY averted lower than one times the gross domestic product per capita. (WHO Commission on Macroeconomics and Health 2001). Compared to other health interventions, these results fall within the middle range of cost per DALY averted (Horton et al. 2017)
}

\section{Breakthrough RESEARCH}

Breakthrough RESEARCH catalyzes SBC by conducting state-of-the-art research and evaluation and promoting evidence-based solutions to improve health and development programs around the world.

Breakthrough RESEARCH is made possible by the generous support of the American people through the USAID under the terms of cooperative agreement no. AIDOAA-A-17-00018. The contents of this document are the sole responsibility of the Breakthrough RESEARCH and Population Council and do not necessarily reflect the views of USAID or the United States Government.

\section{Population Council}

4301 Connecticut Avenue, NW | Suite 280 | Washington, DC 20008 Tel: +1 2022379400 | breakthroughresearch@popcouncil.org

breakthroughactionandresearch.org

Suggested citation: Breakthrough RESEARCH. 2020. "Investing in social and behavio change is cost-effective for increasing modern contraceptive use in Niger," Breakthrough RESEARCH Programmatic Research Brief. Washington DC: Population Council. 